\title{
THREE DIMENSIONAL STRESS-STRAINS ANALYSIS OF A TYPICAL GAS TURBINE BLADE USING FINITE ELEMENT METHOD
}

\author{
SAYEL M. FAYYAD
}

Faculty of Engineering Technology, Al-Balqa Applied University, Salt, Jordan

\begin{abstract}
Energy is extracted in gas turbine systems by expanding hot gases through several passages between fixed stator and moving rotary blades. These blades must have maximum reliability, durability, yield strength and minimum material cost. In this study, High Speed Steel alloys (HSS) and Titanium alloys (Ti-6Al-2Sn.) have been used in the 3D axial turbine blade. The turbine blade has been modelled using Solid works software using finite element analysis to calculate stress, strain, deflection and many other parameters based on a numerical computational method using ANSYS software. An attempt has been made to compute the equivalent of stress, strain and displacement of a typical rotary blade of the gas turbine system and to compare the results obtained with the available data. Attention has been focused on the stress-strain field analysis on the upper and lower surfaces of the blade, and on the turbine blade chord line. The results show the complication of the stress-strain field over turbine blade. From computational results, the use of High-Speed Steel alloys (HSS) in these applications under such cases and assumptions is more preferable to increase the reliability, durability and availability of turbine blades.

KEYWORDS: Turbine Blade, Stress, Strain, Finite Element Method, Three Dimensional Analysis
\end{abstract}

Received: May 09, 2020; Accepted: Jun 29, 2020; Published: Jun 30, 2020; Paper Id.: IJMPERDJUN2020237

\section{INTRODUCTION}

Gas turbine systems are mechanical elements that extract thermal energy from high temperature and high pressure gases and convert it into rotary motion through a system of stator-rotor blades. Rotor and stator blades are subjected to different types of loading such as gas forces, inertia loads and centrifugal forces [1, 2, 3].Due to these combinations of forces, different types of stresses are induced in rotor blade. So stresses and strains on rotor blade provide vital information concerning turbo machine design and lead to design of critical blade section to give maximum strength and blade efficiency [2-4].The present paper deals with stress-strain analysis of a typical rotor blade made of high speed alloy, which is subjected to known velocity gradient that creates sever-stress-strain components on rotor blade to dynamic fluid forces. Due to the complexity of the geometry, a three dimensional solid modeling of the blade was first created, and a finite element package is used for analysis. Stress and strain analysis was done taking into consideration the material behavior of the turbine blade.

A finite element method [FEM] geometrical modeling and mesh generation of the blade were made using a finite element package [ANSYN]. Generally, gas turbine rotor blades have complex three dimensional geometrical structures and behavior, and therefore, numerical simulation methods, can only be used to study stress-strain analysis over these blades. This study provides a simplified approach for the three dimensional rotor blade using a customized 3D FEM.

An introduction to the basic theory of a simplified gas turbine blade design is presented in [4 and 5].The 
papers[6 and 7] studied design and modeling of three dimensional rotor gas turbine blade using MATLAB to solve stressstrain distribution over a turbine blade.

\section{Gas Turbine Blade Materials}

The material used in gas turbine blades should have high temperature performance, high tensile and yield strength as a major requirements. Stress concentration and stress rapture life and creep properties, also of great importance. A wide range of high performance materials such as iron base, steel alloy, and titanium base and super alloys are used for construction of turbines blade. In this paper (HSS) base metal alloy is used and tested, here is the main properties of Ti alloy and HSS blade material. Table 1and 2 Show such properties.

Table 1: Ti Alloy Properties

\begin{tabular}{|c|c|c|}
\hline Model Reference & \multicolumn{2}{|c|}{ Properties } \\
\hline ג & $\begin{array}{r}\text { Name: } \\
\text { Model type: } \\
\text { Default failure } \\
\text { criterion: } \\
\text { Yield strength: } \\
\text { Tensile strength: } \\
\text { Mass density: } \\
\text { Elastic modulus: } \\
\text { Poisson's ratio: } \\
\text { Thermal expansion } \\
\text { coefficient: }\end{array}$ & $\begin{array}{l}\text { Ti-6Al-2Sn-2Zr-2Mo- } \\
\text { 2Cr-0.25Si (SS) } \\
\text { Linear Elastic Isotropic } \\
\text { Max von Mises Stress } \\
\\
1.07 \mathrm{e}+009 \mathrm{~N} / \mathrm{m}^{\wedge} 2 \\
1.16 \mathrm{e}+009 \mathrm{~N} / \mathrm{m}^{\wedge} 2 \\
4650 \mathrm{~kg} / \mathrm{m}^{\wedge} 3 \\
1.23 \mathrm{e}+011 \mathrm{~N} / \mathrm{m}^{\wedge} 2 \\
0.33 \\
9 \mathrm{e}-006 / \text { Kelvin }\end{array}$ \\
\hline
\end{tabular}

Table 2: HSS Properties

\begin{tabular}{|l|r|}
\hline Model Reference & Properties \\
\hline & Name: M4 Hss (1) \\
& Model type: Linear Elastic Isotropic \\
& Default failure Max von Mises Stress \\
criterion: & Yield strength: $2.07 \mathrm{e}+006 \mathrm{~N} / \mathrm{m}^{\wedge} 2$ \\
& Tensile strength: $2.29 \mathrm{e}+006 \mathrm{~N} / \mathrm{m}^{\wedge} 2$ \\
Compressive $2.07 \mathrm{e}+006 \mathrm{~N} / \mathrm{m}^{\wedge} 2$ \\
strength: \\
Elastic modulus: $2.27 \mathrm{e}+011 \mathrm{~N} / \mathrm{m}^{\wedge} 2$ \\
Poisson's ratio: 0.285 \\
Mass density: $7920 \mathrm{~kg} / \mathrm{m}^{\wedge} 3$ \\
Shear modulus: $8.8 \mathrm{e}+010 \mathrm{~N} / \mathrm{m}^{\wedge} 2$ \\
Thermal expansion $11.3 / \mathrm{Kelvin}$ \\
coefficient: \\
\hline
\end{tabular}

\section{Assumptions}

Due to complexity of 3D stress-strain field, and due to strong relationship between mechanical and physical properties and temperature variation, and also due to the need of simplified 3D FEM model, the material is assumed to be linear elastic material, which means that the material may be deformed and will return to its original configuration when load released, also the material is symmetric with respect to every plane and every axis, then the elastic properties are identical in all directions, and also the material is homogeneous, and obeys Hooke's law. 


\section{Finite Element Formulation}

Finite element analysis is a computer based numerical method used to calculate stress, strain, temperature, deflection and many other parameters based on a solution of discredited set of an algebraic equation for a basic form of PDE. In finite element calculations the specified structure is broken down into large number of elements. Each individual element can be described by a simple set of equations, joined together to built the whole structure through a certain shape function, and the generated stiffness matrix here in is a simplified (FEA) model for stress- strain equations of a turbine blade. Internal forces in a gas turbine blade are called stresses. In a finite element a symmetric stress strain tensor components are written as:

$$
\sigma^{T}=\left(\begin{array}{cccccc}
\sigma_{x} & \sigma_{y} & \sigma_{z} & \tau_{x y} & \tau_{y z} & \tau_{z x}
\end{array}\right)
$$

Also strain can be written as:

$$
\varepsilon^{T}=\left(\begin{array}{llllll}
\varepsilon_{x} & \varepsilon_{y} & \varepsilon_{z} & \gamma_{x y} & \gamma_{y z} & \gamma_{z x}
\end{array}\right)
$$

The magnitude of the unit surface $\mathrm{q}_{\mathrm{x}}, \mathrm{q}_{\mathrm{y}}$ and $\mathrm{q}_{\mathrm{z}}$ are related to stresses as:

$$
[q]^{T}=[\hat{\sigma}][n]^{T}
$$

Where

$$
[q]^{T}=\left[\begin{array}{lll}
q_{x} & q_{y} & q_{z}
\end{array}\right] \text {, and }[n]^{T}=\left[\begin{array}{lll}
n_{x} & n_{y} & n_{z}
\end{array}\right]
$$

The effective Von-Mises stress is used to calculate the values of local stress components. Now finite element approximation is used for the displacement equations for $\mathrm{u}, \mathrm{v}$ and $\mathrm{w}$ as follows:

$$
\begin{aligned}
& u=u(x, y, z)=N_{i} u_{i} \\
& v=v(x, y, z)=N_{i} v_{i} \\
& w=w(x, y, z)=N_{i} w_{i}
\end{aligned}
$$

Where: $u_{i}, v_{i}, w_{i}$ are nodal degrees of freedom, $N_{i}=N_{i}(x, y, z)$ are suitable interpolation shape function. The final solution can be written as:

$$
u(x, y, z)=\left[\begin{array}{c}
u \\
v \\
w
\end{array}\right]=\left[\begin{array}{cccccc}
N_{1} & 0 & 0 & N_{2} & 0 & \ldots \\
0 & N_{1} & 0 & 0 & N_{2} & . . \\
0 & 0 & N_{1} & 0 & 0 & . .
\end{array}\right]\left[\begin{array}{c}
u_{1} \\
v_{1} \\
w_{1} \\
\ldots
\end{array}\right]=N^{T} d
$$


The elements of strain vector can be computed as:

$$
\mathcal{\varepsilon}=\left[\begin{array}{c}
\varepsilon_{x} \\
\varepsilon_{y} \\
\varepsilon_{z} \\
\gamma_{x y} \\
\gamma_{y z} \\
\gamma_{z x}
\end{array}\right]=B^{T} d
$$

Where $B$ is the gradient matrix given as:

$$
B^{T}=\left[\begin{array}{ccccc}
\frac{\partial N 1}{\partial x} & 0 & 0 & \frac{\partial N 2}{\partial x} & . . \\
0 & \frac{\partial N 1}{\partial y} & 0 & 0 & \ldots \\
0 & 0 & \frac{\partial N 1}{\partial z} & 0 & \ldots
\end{array}\right]
$$

Where $d$ vector can be written as:

$$
d=\left[\begin{array}{l}
u_{1} \\
v_{1} \\
w_{1} \\
u_{2} \\
v_{2} \\
w_{2} \\
\cdots
\end{array}\right]
$$

And the elements of the stiffness matrix $\mathrm{K}$ are evaluated as:

$$
K=\iiint_{V}[B]^{T}[D][B] d V
$$

\section{RESULTS AND DISCUSSIONS}

The turbine blade is represented as shown below in fig. 1 below. It is fixed from one end as shown and the flow is over the free surfaces of the blade. 


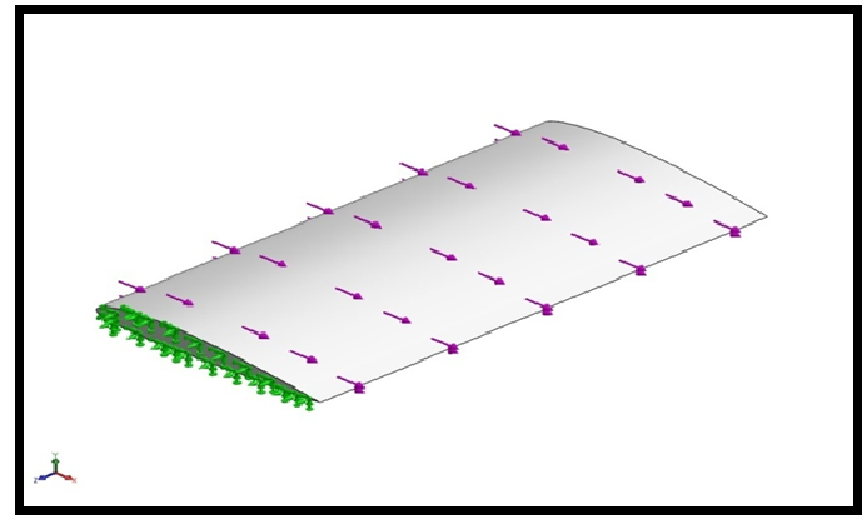

Figure 1: Turbine Blade Model.

Fig. 2 shows the meshing of the studied blade.

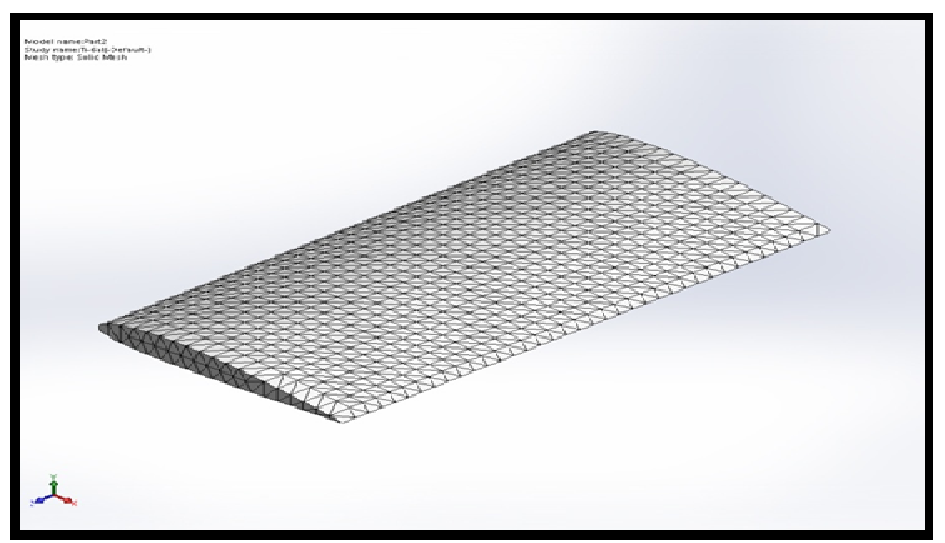

Figure 2: Mish of the Turbine Blade.

Fig. 3 and 4 shows the Von-Mises stresses distribution in both Titanium alloys and HSS blades

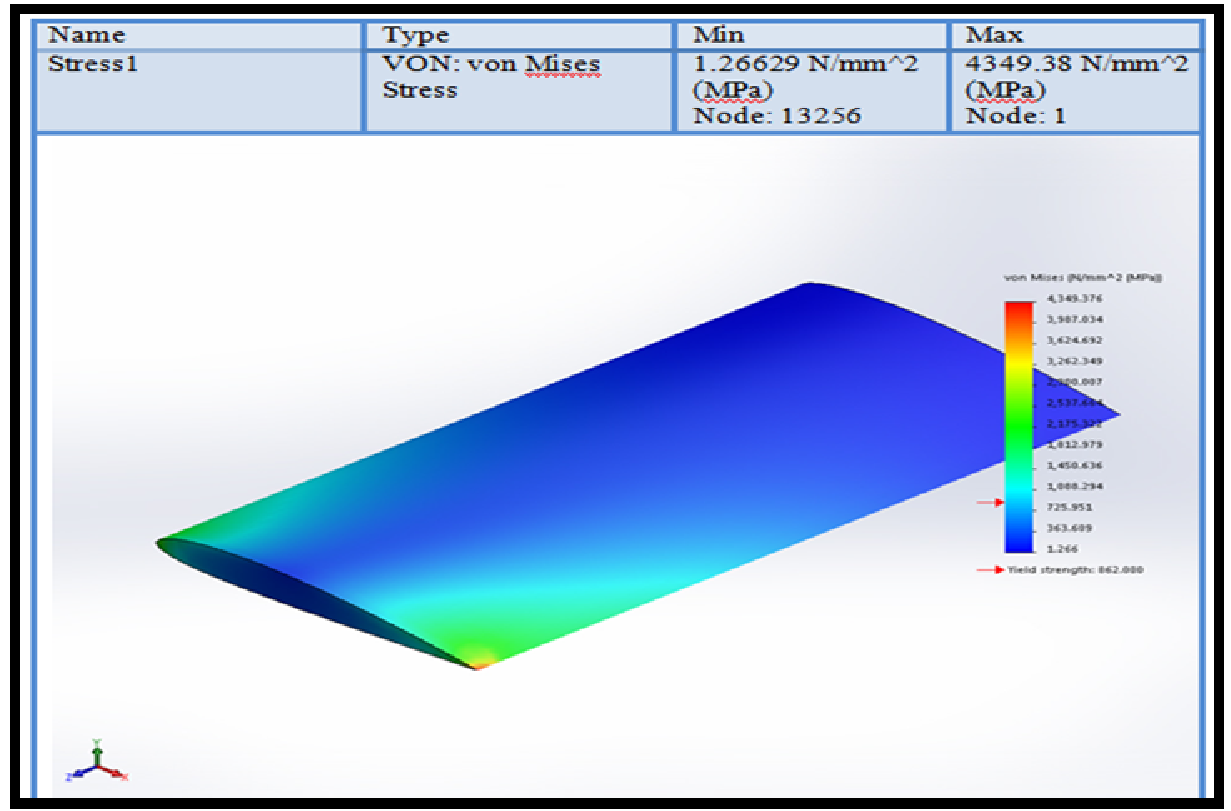

Figure 3: Von-Mises Stresses on the Ti Alloy Blade. 


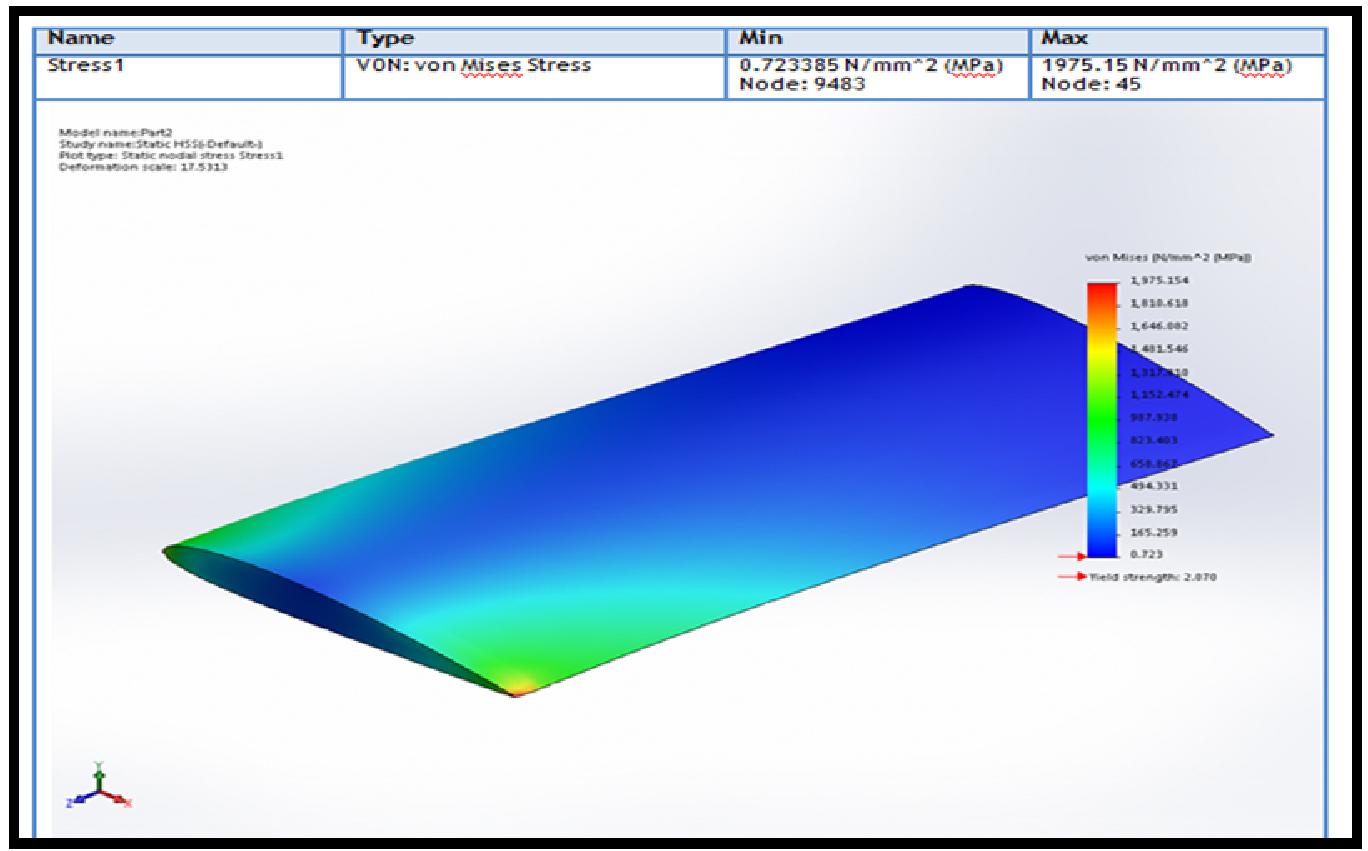

Figure 4: Von-Mises Stresses on HSS Blade.

It can be noticed that the stresses distribution on the blade is the same but with different values of the maximum and minimum values of stress as shown in Fig.3 and 4. The maximum value of stress in the case of Ti alloy is more than HSS blade. Fig. 5 and 6 show the displacement in x-direction of the blade for both Ti alloy blade and HSS blade respectively.

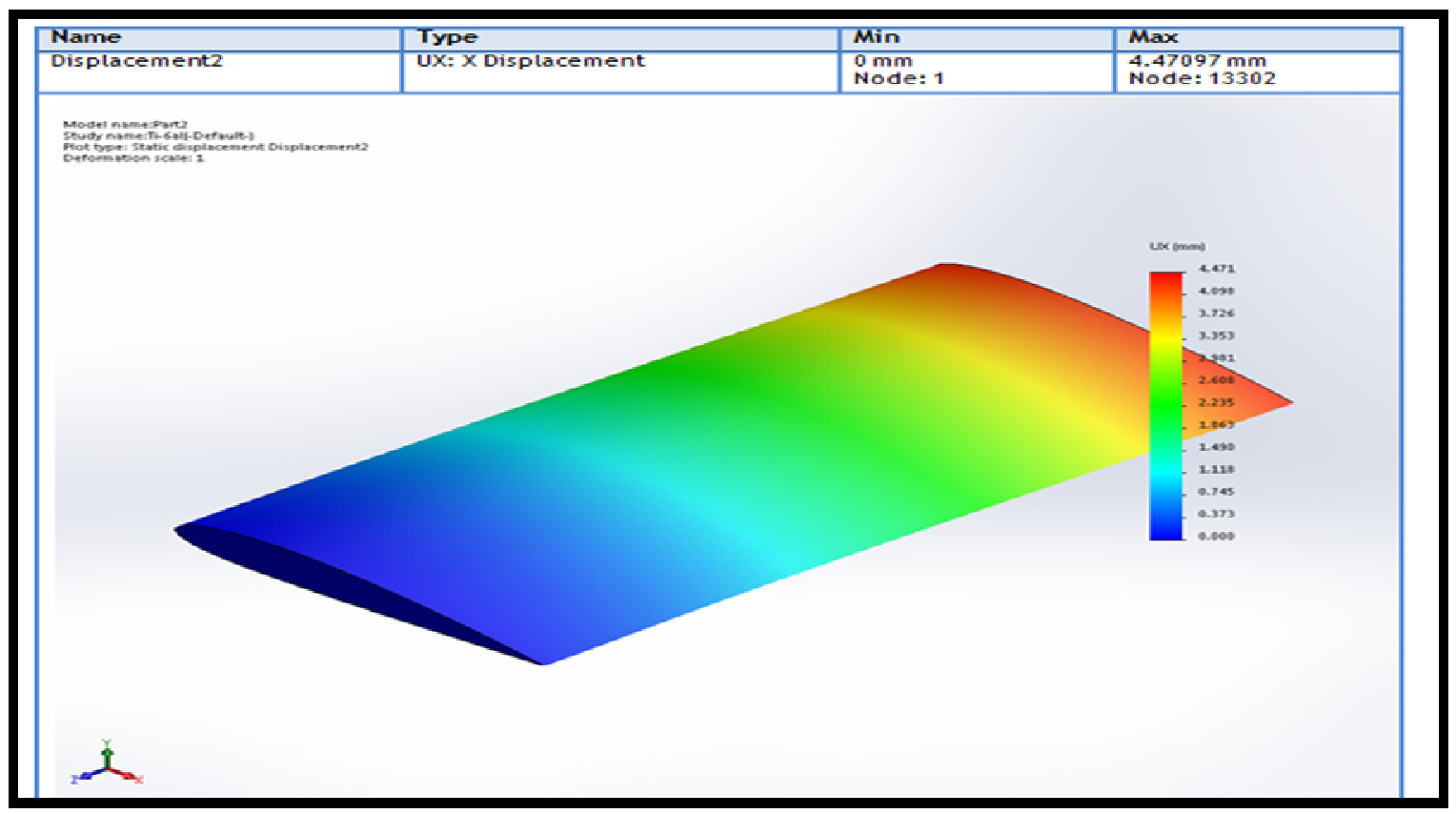

Figure 5: Displacement of Both Blades in x-Direction for Ti Alloy. 


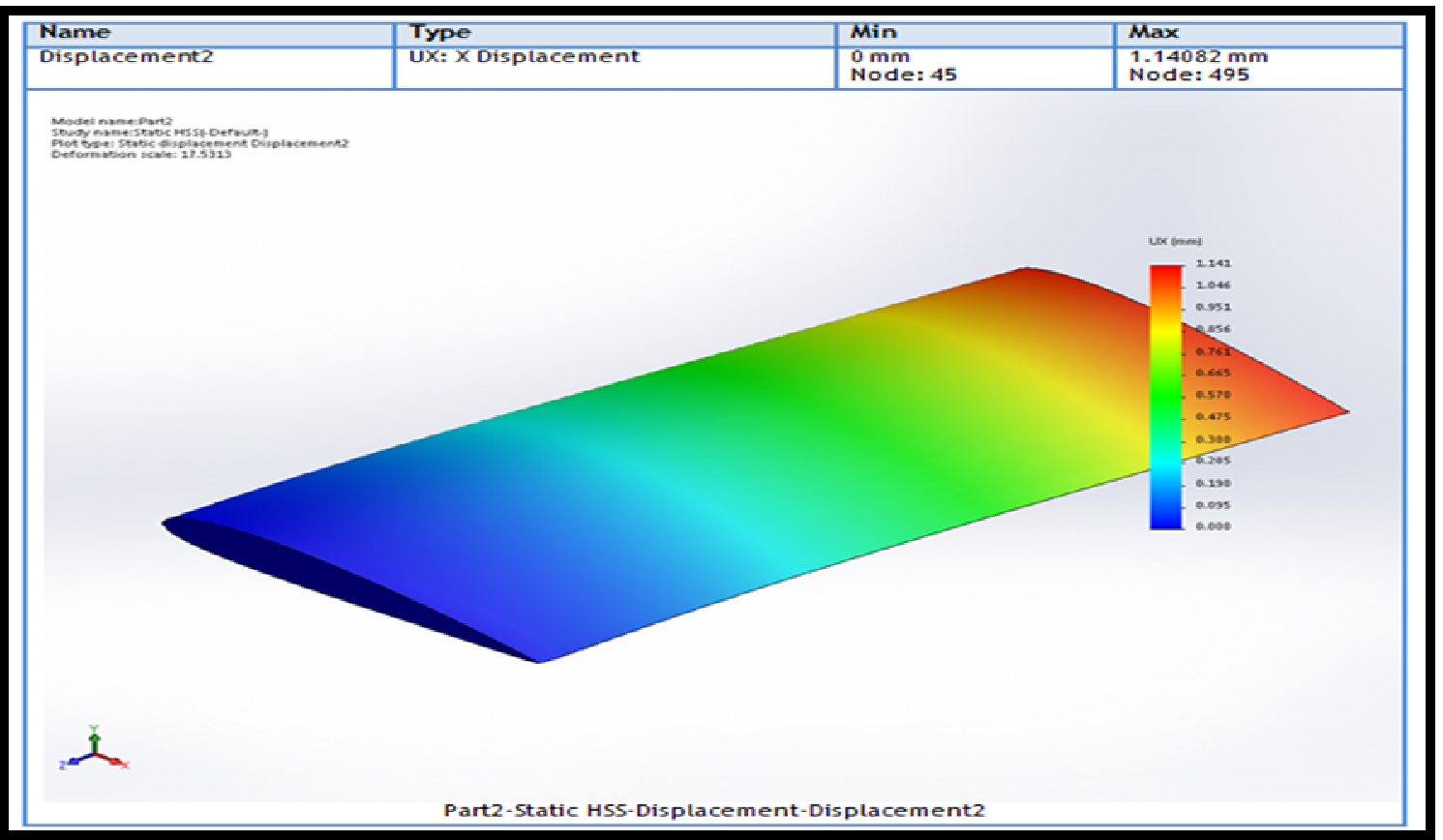

Figure 6: Displacement of Both Blades in x-Direction for HSS Blades.

Fig.7 and 8 show the resultant displacement for both types of blades respectively.

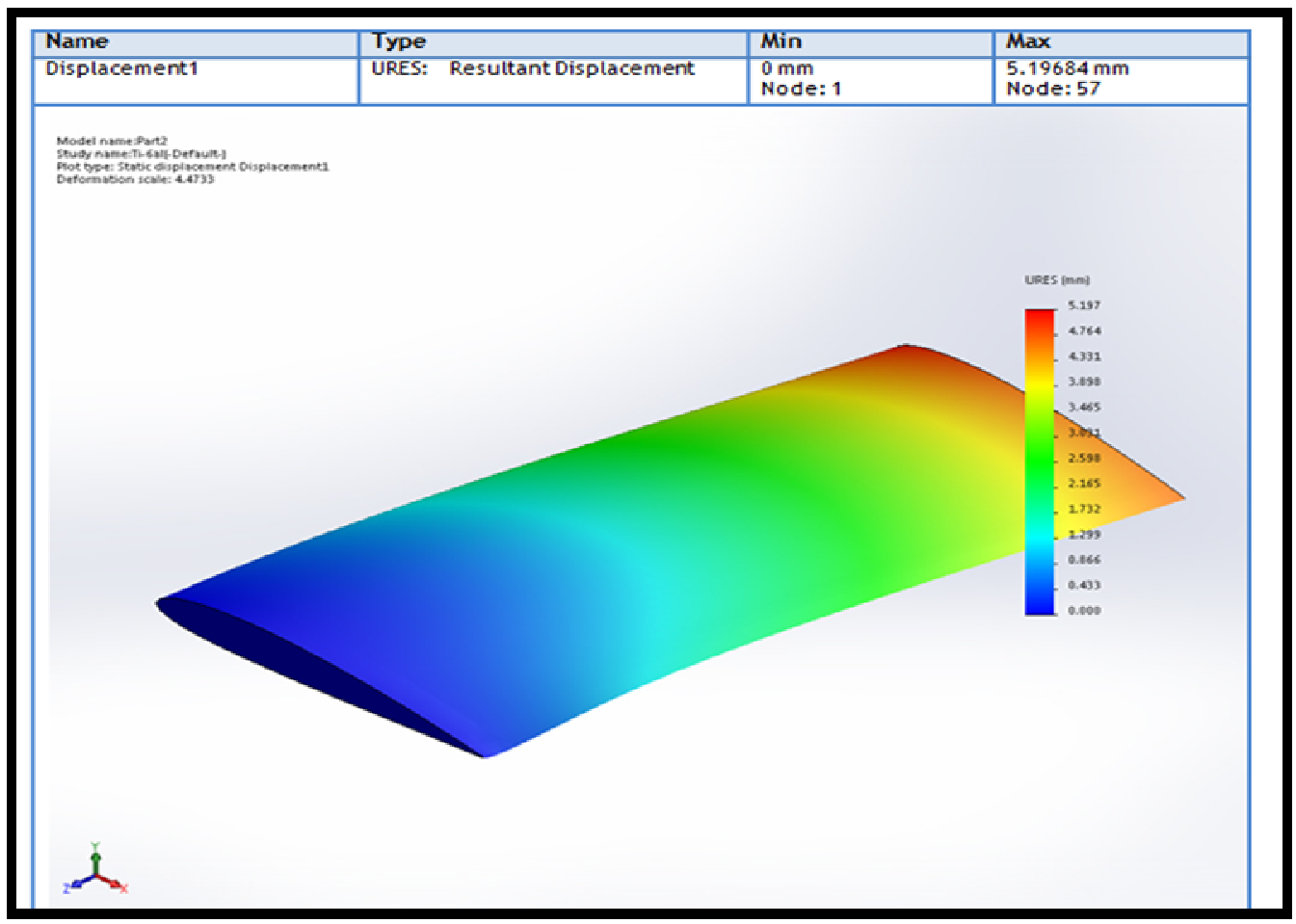

Figure 7: Resultant Displacement of Ti Blades. 


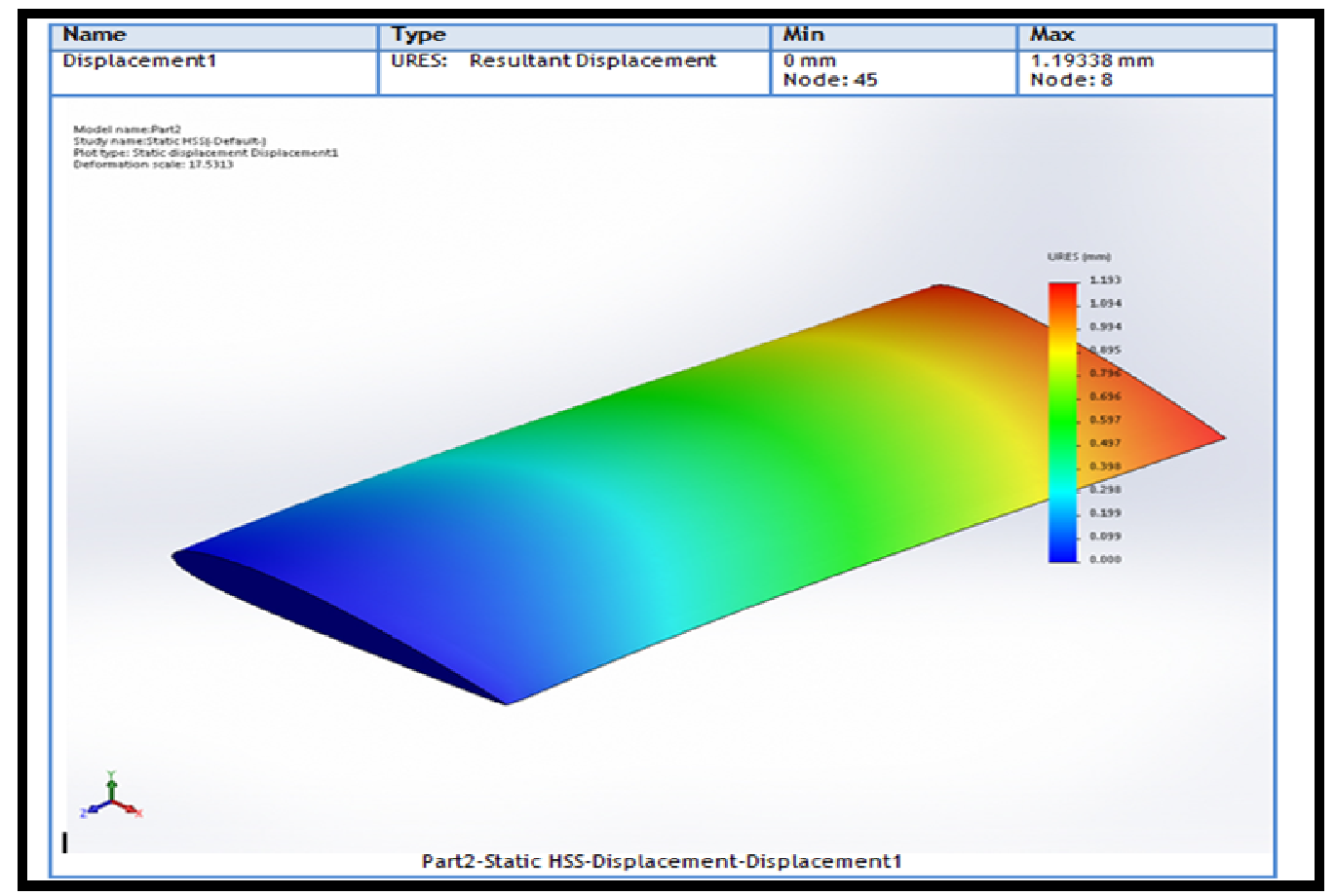

Figure 8: Resultant Displacement of HSS Blades.

Fig. 9 and 10 show the strain in both types of blade.

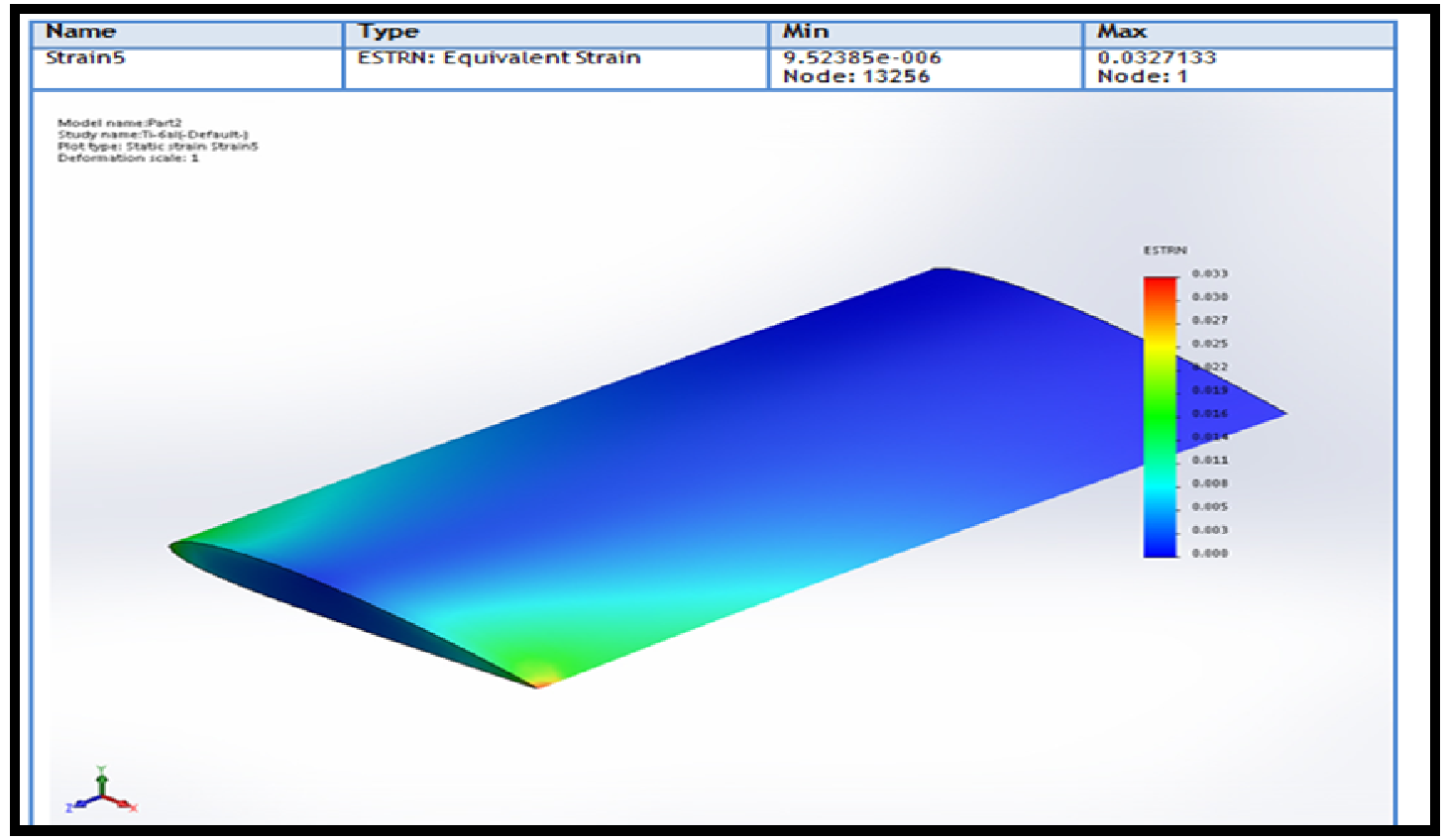

Figure 9: Strain of Ti Alloy Blade. 


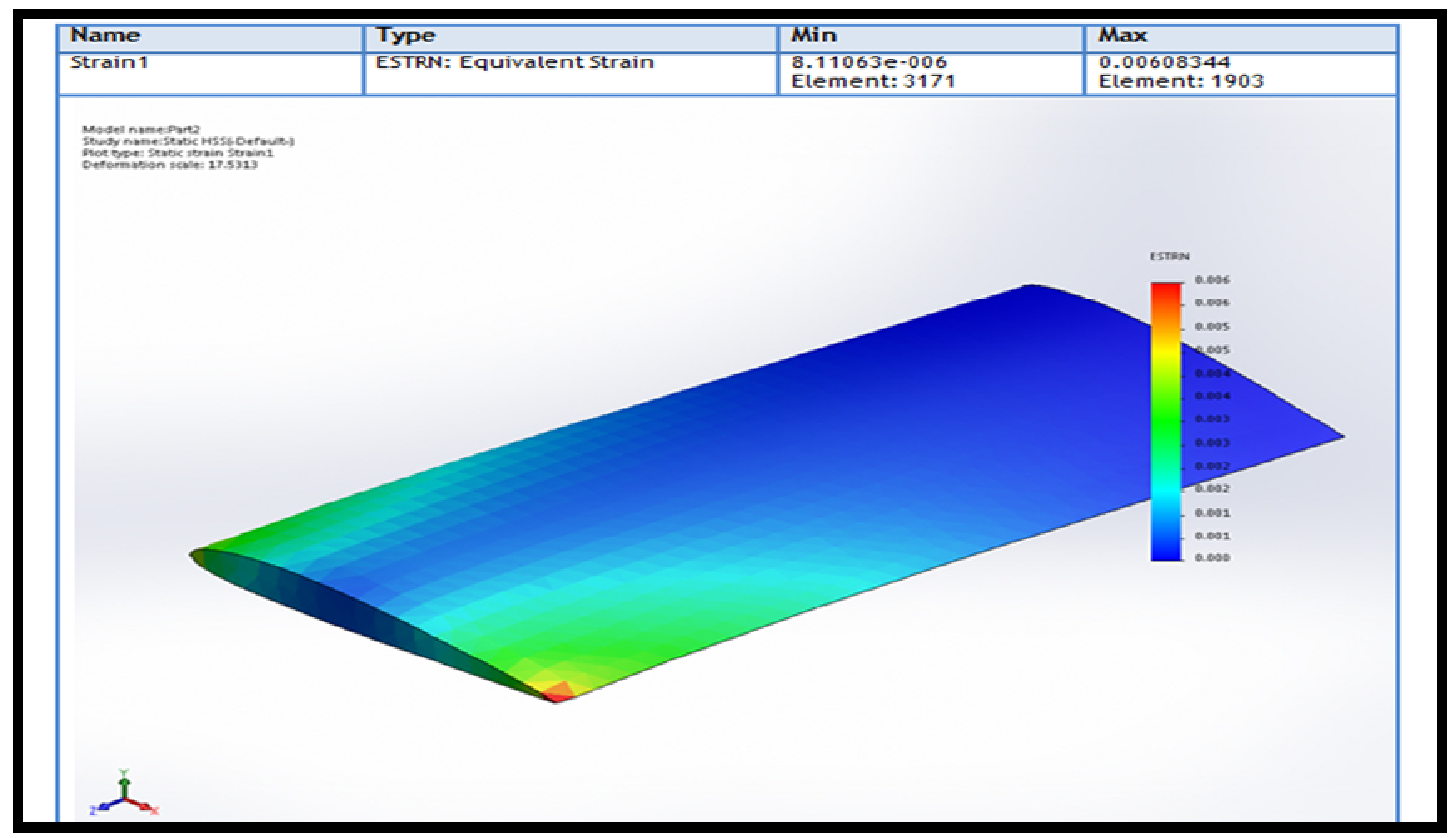

Figure 10: Strain of HSS Blade.

Fig. 11 and 12 show the stress distribution on the blades surface of the two blades' types.

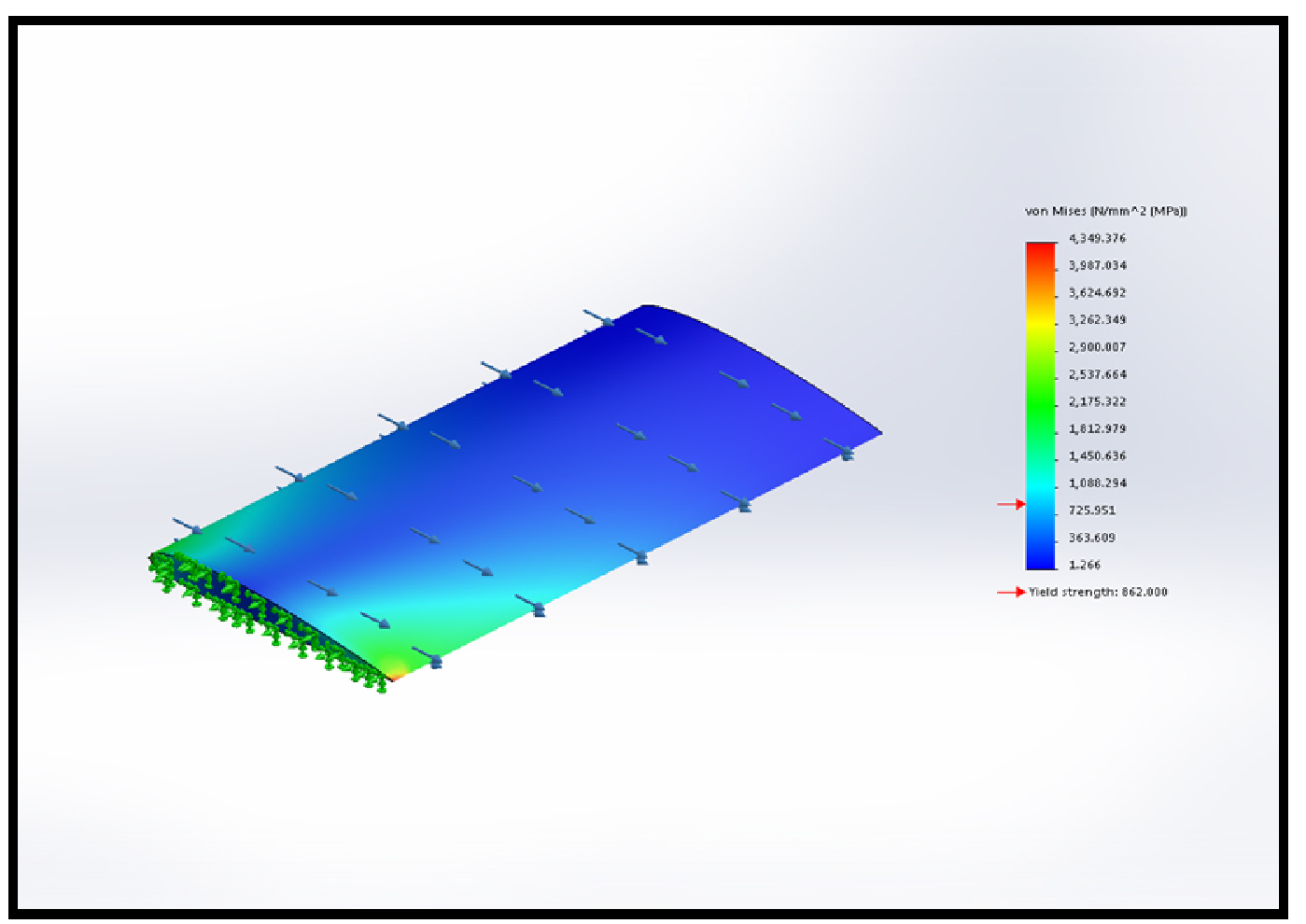

Figure 11: Stress Distribution on the Surface of Ti-Alloy Blade. 


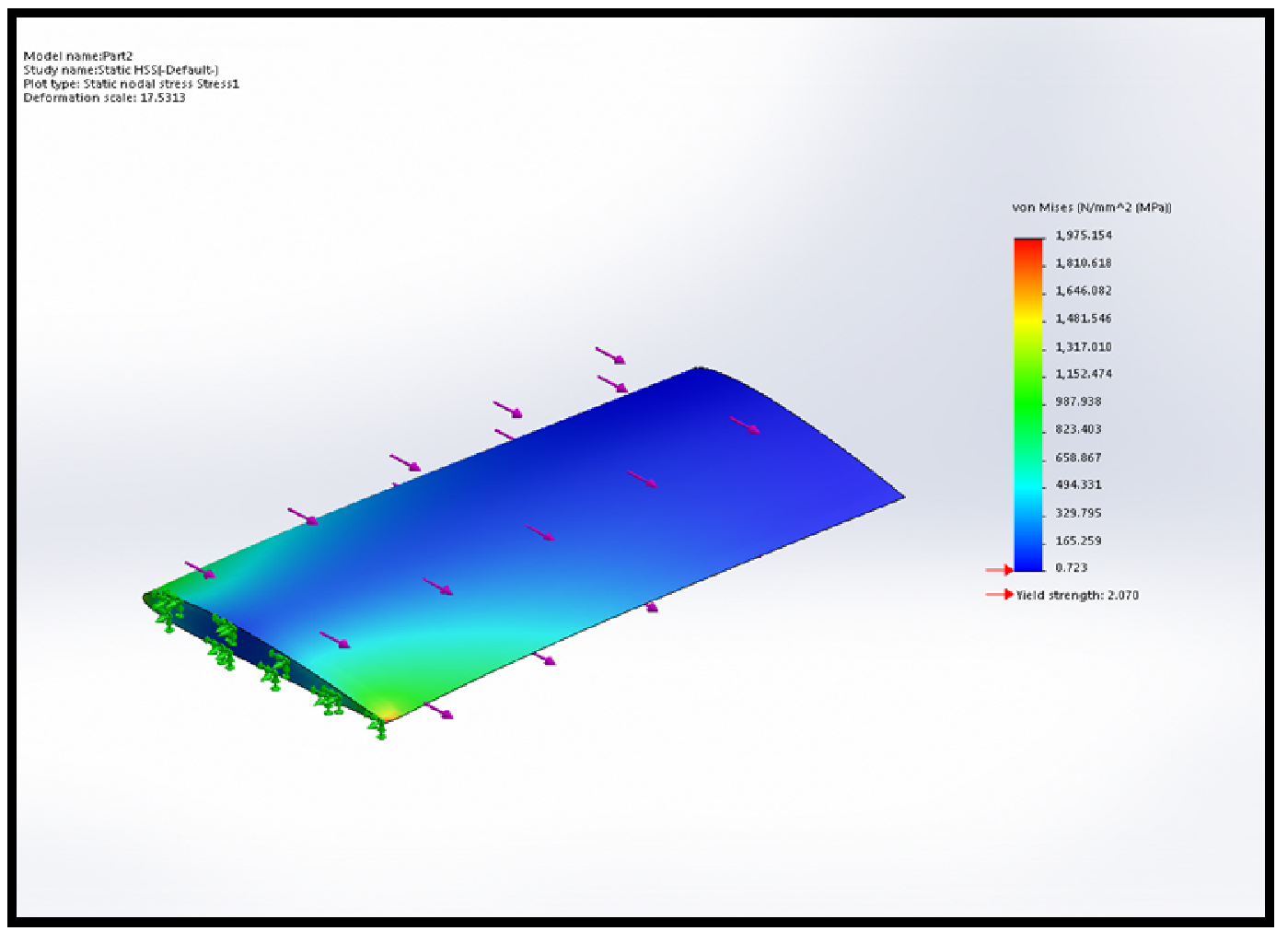

Figure 12: Stress Distribution on the Surface of the HSS Blade.

Figure 13 and 14 show the stress values for both types of blades along the blade points along the blade span.

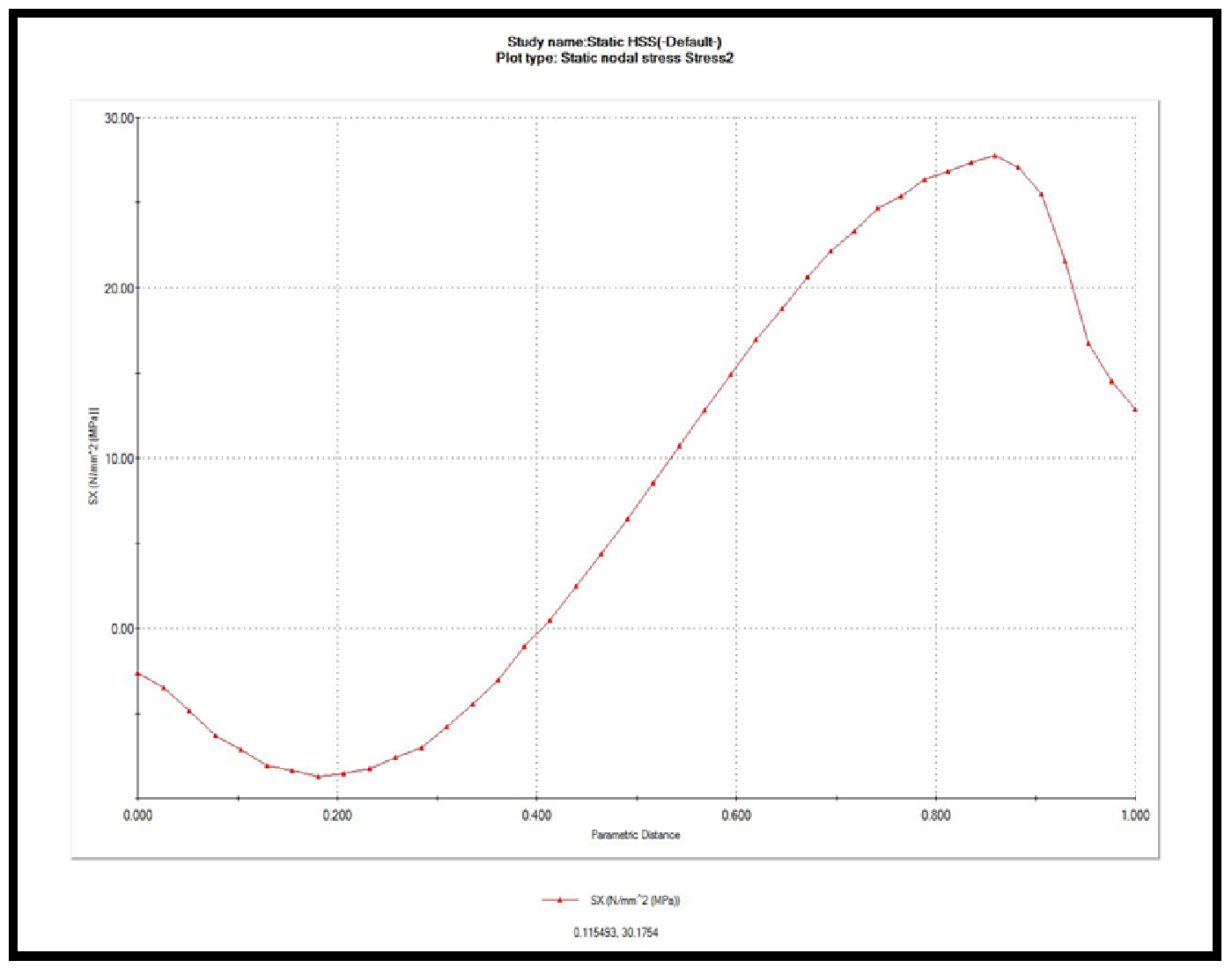

Figure 13: Stress Values of the HSS Blade. 


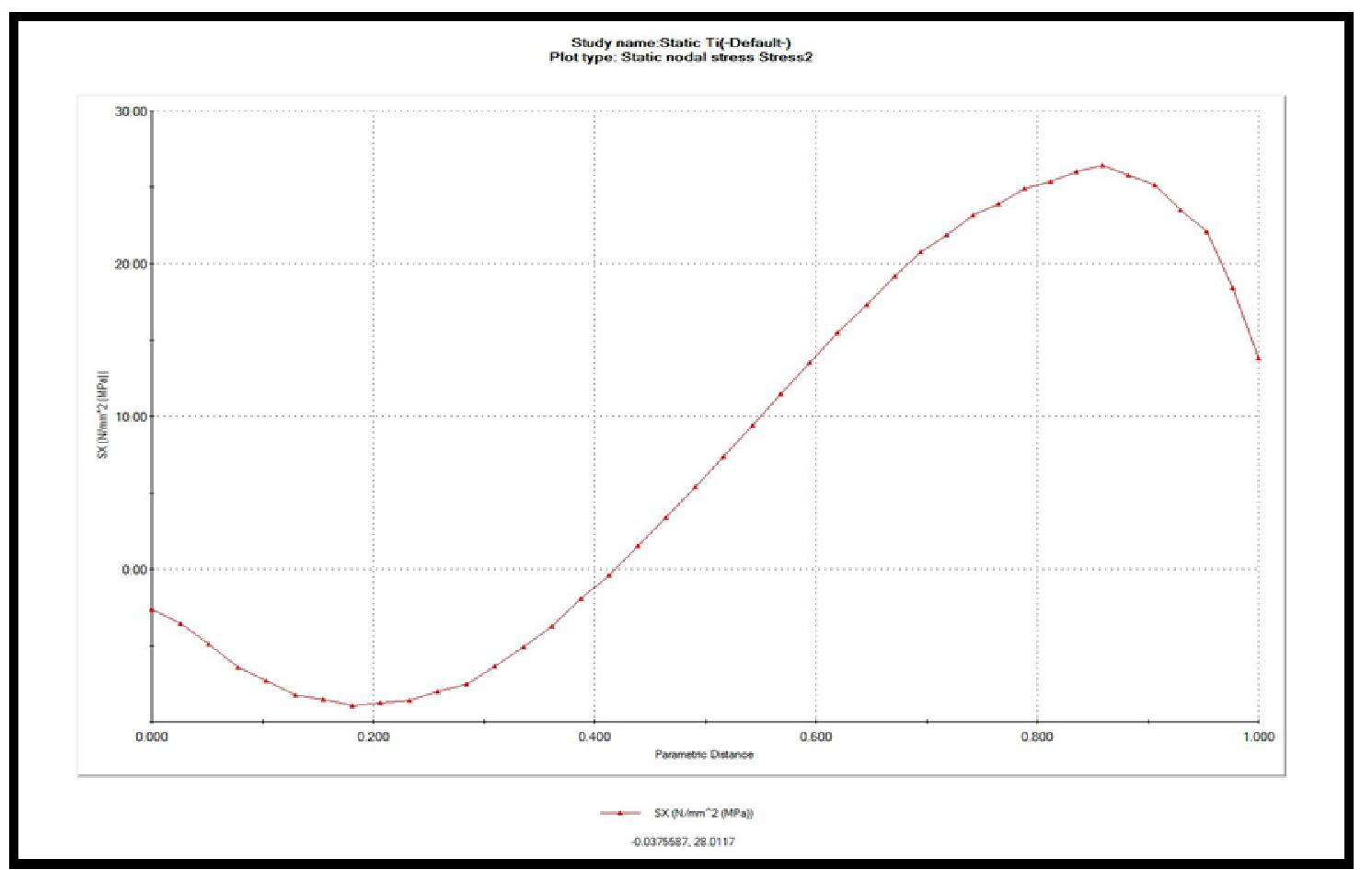

Figure 14: Stress Values of the Ti Alloy Blade.

It can be noticed from last two figures that HSS blades stress values are higher than that of Ti blades as the blade span from fixed end increases. This is related to material properties of the blade. So with the same conditions of work for the two blades HSS can possesses more stress and then it is preferable than Ti alloy blades.

\section{CONCLUSIONS}

In this study, structural analysis of a finite element of 3D axial turbine with two different types of turbine blades made of two different material compositions i.e. High-Speed Steel alloys (HSS) and titanium alloys (Ti-6Al-2Sn.) in the high stress zone was done.

Three parameters which are stress, displacement and strain were calculated based on a numerical computational method using ANSYS software. The computational results were fully analyzed. From the analysis it was observed that:

Three parameters were calculated: stress, displacement and strain based on the method of numerical calculation using ANSYS software. The computational results were fully analyzed. From the analysis it was observed that:

- It was found that the equivalent stress, displacement and strain in High-Speed Steel alloys (HSS) are higher than that of Titanium alloys (Ti-6Al-2Sn).

- From computational results, the use of High-Speed Steel alloys (HSS) in these applications under such cases and assumptions is more preferable to increase the reliability, durability and availability of turbine blades 


\section{REFERENCES}

1. Vaishaly F, Ramarao B.S.V, Finite Element Stress Analysis of a typical steam turbine blade, International Journal of Sciences and Research (IJSR) Vol. 4, issue 7, July 2015.

2. Elhefny Amr, Guazhu, Stress Analysis of Gas Turbine Blade under different loads using finite element modeling, The American Society of Mechanical Engineers, (ASME).org, 2016. Paper 190.

3. Srikanth G, Bajaj D, Naidu K.S, Structural and thermal finite element analysis of gas turbine rotor blade, IJMETMR, Vol. 2, Issue N:10 October, 2015.

4. Mohammad B A, Failure analysis of gas turbine blade using finite element analysis, (IJMET), Vol.7, Issue 3, June 2016, pp 299-305.

5. Martine R, Reis L, Mendes M, Finite element prediction of stress strain field on sandwich composite, xv Portuguese conference on fracture, pcf 2016 10-12 Feb 2016, Oaco de Arcos, Portugal.

6. Saeed RA, Galybin AN, Simplified model of the turbine runner blade, Engineering failure analysis, 16 (2009) $2473-2484$.

7. Song F, Ni Y, Tan Z, Optimization Design Modeling and Dynamic Analysis for Composite Wind Turbine Blade, International Workshop of Automobile, Power and Energy Engineering, Procedia Engineering $1 \quad 6$ (2011) pp 369-375.

8. KimB, Lee JM, Hwang Y, Determination of engineering strain distribution in a rotor blade with fiber Bragg grating array and a rotory optic coupler, optics and laser in Engineering, 46 (2008), pp 758-762.

9. Negru R, Muntean S, Marsavinal L, Resiga RS, Pasca N, Computation of stress distribution in a Frances turbine runner induced by fluid flow, computational material science, 64 (2012) 253-259.

10. Kauthalkar S P, Shikarwar MDS, Sharma P K, Analysis of thermal stress distribution Pattern on gas turbine blade using Ansys, International Journal of Engineering, Education and Technology, Vol. 1, Issue 2, 2013.

11. VT, P S U, Reddy PLVG, Manjunath C J, Design and analysis of gas turbine blade, International journal of innovative research in science eng. and tech, Vol 3, issue 6, 2014.

12. Vale $T$ de $\mathrm{Ol} \mathrm{V}$, Villar $\mathrm{G}$ da C, Menezes JC, Methodology of structural integrity analysis of gas turbine blades, AerospTechnolManag., Vol. 4, N: 1 pp 51-59 Jan-Mar 2012.

13. Singhmar S, Kumar M, Gupta M, Shadig M, Finite element analysis of axial flow turbine blade, International journal of modern engineering research (IJMER), Vol. 5, Issue 2, 2015.

14. Bhatti M A, Advanced topics in finite element analysis of structures, book, 2006, John Wiley and Sons New York.

15. Segerlind L J, Applied finite element analysis, second edition, 1984, book, John Wily and Sons.

16. Patel V, Aijaz, M A, Stress simulation of general steam turbine blade materials, International journal of engineering sciences and research technology ISSN:2277-9655, Patel, 2 (7), pp. 1658-1660, July 2013.

17. Kumar, Shailendra, et al. "A Comparative Analysis of Advance Three Dimensional Video Coding for Mobile Three Dimensional TV." International Journal of Electronics and Communication Engineering (IJECE) 3.5 (2014):59-64

18. Nambi, S. Selvan, and G M Joselin Herbert. "Manufacturing of Proto Type Wind Turbine Blades using Rapid Prototype Technology." International Journal of Mechanical and Production Engineering Research and Development (IJMPERD) 8.2 (2018):103-112 
19. Wu, Jong-Shyong, Ching-A N Huang, and Huei-Jou Shaw. "Dynamic Analysis of the S-Type Fluid-Conveying Steel Pipe for TSEN-WENG Reservoir using Finite Element Method." International Journal of Civil Engineering (IJCE) 7.1 (2018):9-30

20. Muhammad, Abdul Kadir, Shingo. Okamoto, and Jae Hoon Lee. "Comparison between the One Piezoelectric Actuator and the Two Ones on Vibration Control of a Flexible Two-Link Manipulator Using Finite Element Method." International Journal of Mechanical Engineering (IJME) 5.1 (2016): 25-42.

21. Job, VICTOR M., and S. Rao Gunakala. "Unsteady MHD Free Convection Couette Flow between Two Vertical Permeable Plates in the Presence of Thermal Radiation Using Galerkin's Finite Element Method." International Journal of Mechanical Engineering (IJME) 2.5 (2013): 99-110.

22. Sri, Navya, and A. Chennakesava Reddy. "Formability of Elliptical SS304 Cups in Single Point Incremental Forming Process by Finite Element Method." IMPACT: International Journal of Research in Engineering \& Technology (IMPACT: IJRET) 4.11 (2016): 9-16.

23. Kollek, Wactaw, and Urszula. Radziwanowska. "The modernization of gear micro pump casing with the use of finite element method." IMPACT: International Journal of Research in Engineering \& Technology (IMPACT: IJRET) 2.7 (2014): 69-76. 

